\title{
EFFECTIVE MARKETING COMMUNICATION EFFORTS OF SPORTS DEVELOPMENT INITITAIVES: A CASE STUDY OF THE PUBLIC SECTOR IN THE UNITED KINGDOM
}

\author{
Ian Arnott, University of Northampton, United Kingdom
}

\begin{abstract}
Questions could be had that there should be an increased focus in the area of marketing communications of sports development initiatives within the public sector to its consumers. Drawing upon marketing theory and sports marketing literature the research argued on how some of the tools and variables that make up marketing communications such as the marketing mix (product, price, place, and promotion) work in harmonization with the promotional mix? Also as to how they sway the consumer's decision when consuming various types of development initiatives to increase participation in sport. Previous research (Westerbeck \& Shilbury, 1999) has looked at what impact the marketing mix has had in the way of facility lead marketing and there was also some tenuous links by Schiender \& Bradish, (2006) to that of place as a means of the distribution of the sports development initiatives. However this was one element of the marketing mix and not how all the variables could or worked in harmonization with each other or more in importantly the psycho-graphical affect upon increasing participation in sport as the sport development initiative does. Many would argue (Houlihan, 1997; Thomas, 2000) that there has been a non-interventionism approach to the development of sports which is reinforced by Green \& Houlihan, (2006) who referred to it in the UK as it more like a "piece meal approach" or unstructured (Houlihan, 1997).

An understanding of the consumer psyche was of great importance to this research, which was similar to that conducted by Bradish et al. (2001) when they looked at segmenting the market place in sport. However, their research was slightly biased towards 200 males, where this research study included both male and female responses.

Therefore primary aim of the research was to investigate the marketing mix variables and how these impacted consumers' selection of a sports development initiative. Data for this case study was collected from a public sector sports facility located in the United Kingdom (UK) focusing on the gender and age of the sport development consumer as well as the main sport in which the consumer participated. A self administered piloted questionnaire was carried out in December (2009) with twenty consumers $(n=10 \%)$. Developments were then made to the questionnaire before it was administered to the sports development initiatives participants $(N=200)$. The participant's abilities were varied, and the questionnaire, to cater for this diversification, contained a range of nominal, ordinal, and interval questions. To gain a better perspective of the participants involved in this study were individuals who attended the sports facility who pay and play for the various initiatives that were run at the facility. The number of sports development initiative consumers used in this study was 92 males and 108 females. Historically, participation in sport in Great Britain, in the years $1996-2002$, women took the lead in participation in sport, toppling men by a mere 1,021 in total (Sport England, 2005). The findings suggested that people selecting a sport development initiative based their choices on the marketing mix variable of place. In terms of promotion, the findings revealed that word of mouth communications had an influence on sports development initiatives.
\end{abstract}

References are available on request 